\title{
Noncardiac chest pain: systematic review of the literature on prognosis
}

\section{Edwin Meresh John Piletz \\ Angelos Halaris}

Department of Psychiatry and Behavioral Neurosciences, Loyola University Medical Center, Stritch School of Medicine, Maywood, IL, USA

Video abstract

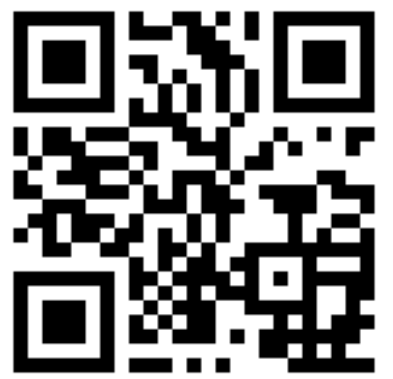

Point your SmartPhone at the code above. If you have a $O R$ code reader the video abstract will appear. Or use: http://youtu.be/04YwomTyFsM
Correspondence: Edwin Meresh Department of Psychiatry and Behavioral Neurosciences, Stritch School of Medicine, Loyola University Medical Center, 2160 South First Avenue, Bldg 105, Rm 1940, Maywood, IL 60I53, USA

Tel +l 7082163274

Email emeresh@lumc.edu
This article was published in the following Dove Press journal: Research Reports in Clinical Cardiology

Background: Noncardiac chest pain (NCCP) is defined as persistent angina-like chest pain with no evidence of cardiac disease. There is some controversy about the long-term morbidity and mortality outcomes of NCCP patients. Many studies have found no significant differences in death rates in chest pain patients without coronary artery disease compared to the general population. However, studies that include longer follow-up periods and a better characterization of the NCCP population reveal a twofold elevation in the relative risk of adverse cardiac events over 5-26 years. This review sought to identify studies in relation to cardiovascular and psychological prognosis of NCCP patients.

Methods: PubMed database and reference lists from relevant publications were reviewed. Inclusion criteria were systematic reviews, prospective studies, and retrospective surveys from 1970 to 2011. Search terms were as follows: chest pain, noncardiac chest pain, nonspecific chest pain, unexplained chest pain, prognosis of noncardiac chest pain, prognosis of angina with normal angiography, and angina with normal coronary arteries.

Results: Studies supporting worse outcome (cardiac morbidity and mortality; $n=16$ ) included 173,875 patients with mean age 57 and mean length of follow-up 7.5 years. Studies supporting good outcome $(n=25)$ included 244,998 patients with age 50 and length of follow-up 5 years. Articles supporting poor psychological outcome $(n=9)$ included 3,987 patients and length of follow-up 2 years.

Conclusion: There are mixed data on long-term morbidity, cardiovascular adverse events, and mortality of NCCP patients. Some studies provide supporting evidence for poor outcome, while others provide evidence for positive outcome. However, many patients with NCCP have prolonged psychosocial comorbidity. The heterogeneity of NCCP and study populations limited definitive conclusions. However, many patients with NCCP have psychiatric morbidity and poor quality of life. Several questions remain about NCPP with respect to the psychopathology and pathophysiology of this condition. Whether NCCP patients have good or bad outcome requires careful risk stratification.

Keywords: chest pain, noncardiac chest pain, anxiety, angina with normal coronary arteries, microvascular angina, prognosis

\section{Introduction}

Chest pain is a common and alarming patient complaint, amounting to more than 6 million cases in the USA annually. ${ }^{1}$ After extensive and costly evaluations, many of these patients receive the diagnosis of noncardiac chest pain (NCCP), defined as persistent angina-like chest pain with no evidence of cardiac impairment after a reasonable cardiac evaluation. NCCP is a heterogeneous disorder caused by various 
conditions (Table 1). Several studies have supported evidence for anxiety and mood disorders and pain perception abnormalities. Inflammation and microvascular angina are also implicated. Patients can have normal epicardial coronary arteries but still have microvascular dysfunction. ${ }^{2}$ Acid reflux may induce chest pain. Gastroesophageal reflux disease, esophageal motility disorders, musculoskeletal disorders, breathing disorders, depression, and anxiety are implicated as causal factors. ${ }^{3,5,8}$ Few studies support a role of antidepressants in treating pain perception and the comorbid anxiety and depression. NCCP is considered a benign problem with various psychopathological comorbidities.

While chest pain can be a bona fide symptom of coronary artery disease (CAD), not infrequently, the origin of chest pain remains elusive even after thorough cardiovascular evaluations. Approximately $30 \%$ of all coronary angiograms prove to be negative for significant $\mathrm{CAD}$, and these patients are thus diagnosed with NCCP. ${ }^{3}$ More than 3 million patients are admitted with NCCP each year, costing over $\$ 10$ billion annually, ${ }^{4}$ and are given this "diagnosis of exclusion", 6 since no organic medical cause to explain their complaint could be ascertained. NCCP is associated with exceedingly high health-care costs due to activity limitations for the patients, health-care utilization, repeated admissions to coronary care units, and further catheterizations. Regardless of the etiology of the pain, NCCP patients suffer, and they experience poor psychological and quality-of-life outcomes. ${ }^{7}$ In view of the fact that the condition is poorly understood, these patients do not receive optimal care. ${ }^{8} \mathrm{~A}$ high percentage of these patients continue to experience chest pain for many years and be consumers of medical resources. The question is how many of these patients eventually develop cardiovascular morbidity and mortality. ${ }^{9-13}$ Unexplained chest pain is often comorbid with anxiety, depression, and somatoform disorders. ${ }^{1-21}$ In a recent study by White et al, the comorbidity of psychiatric conditions and NCCP was examined prospectively in a cohort of 231 NCCP patients free of a current or lifetime cardiac diagnosis. The authors found that $44 \%$ of the NCCP patients suffered from a current Axis I psychiatric diagnosis, with anxiety disorders being most prevalent at $41 \%$ and mood disorders at $13 \% .{ }^{22}$ Patients with NCCP may also have exaggerated or abnormal cardiac pain perceptions, ${ }^{23}$ visceral hyperalgesia, ${ }^{24}$ and/or abnormal cardiac sensitivity to a variety of stimuli. ${ }^{25}$ Treatment of NCCP includes psychotherapy and psychotropic medications, such as antidepressant and antianxiety drugs. ${ }^{26}$

Studies that include longer follow-up periods and a better characterization of the heterogeneous NCCP population reveal about a twofold elevation in the relative risk of adverse cardiac events (cardiovascular morbidity and mortality) over 5-26 years in NCCP patients. ${ }^{9-13}$ Due to the frequency of significant psychiatric comorbidity associated with NCCP, could it be that the known association between anxiety, depression, panic disorder, and cardiovascular disease (CVD) is responsible for the long-term morbidity and mortality of NCCP? It has been shown that acute and chronic anxiety can be associated with sudden cardiac death and CAD. ${ }^{27,28}$ Depression is an established risk factor for CVD with a 2.0 relative risk of adverse cardiovascular events. ${ }^{29,30}$ Panic disorder has been associated with hypertension, small vessel cardiac ischemia, and lipid abnormalities..$^{31,32}$ Thus, associations could exist between NCCP, depression/anxiety, and a higher risk of cardiovascular morbidity and mortality. A large proportion of older women report levels of depressive symptoms that are significantly related to increased risk of CVD death and all-cause mortality, even after controlling for established CVD risk factors. ${ }^{30}$ Elderly women diagnosed with nonspecific chest pain may be at increased cardiovascular risk. ${ }^{33-35}$ In women with suspected myocardial ischemia, depression was a strong predictor of increased risk of cardiac events. ${ }^{36}$ However, the causal relationship between coronary heart disease (CHD) risk factors in the psychiatric population and increased NCCP morbidity and mortality risk, if any, is unclear. It remains unknown if psychiatric disorders can contribute to NCCP and thus lead to any CAD, or if any other CVD risk factors exist that are present in the NCCP population. Between $32 \%$ and $64 \%$ of patients with chest pain

Table I Causes of NCCP

\begin{tabular}{ll}
\hline Esophageal causes & GERD, esophageal dysmotility-nutcracker esophagus, achalasia, diffuse esophageal spasm, HTLES \\
Stomach & Peptic ulcer, gastritis \\
Musculoskeletal & Costochondritis, Tietze syndrome, fibromyalgia, muscle injury \\
Pulmonary & Pleuritis, pneumonia, intrathoracic masses \\
Visceral hypersensitivity & Esophageal hypersensitivity \\
Psychological comorbidity & Panic disorder and anxiety, depression \\
Malignant disease & Gastrointestinal, chest wall, breast \\
Miscellaneous & Drug-induced pain, sickle cell disease, herpes zoster, pericarditis, myocarditis \\
\hline
\end{tabular}

Abbreviations: GERD, gastroesophageal reflux disease; HTLES, hypertensive lower esophageal sphincter; NCCP, noncardiac chest pain. 
and normal coronary angiograms are smokers. ${ }^{37}$ In patients with chest pain and negative coronary angiograms, some studies have identified diminished coronary flow velocity reserve and aortic distensibility, ${ }^{38}$ microvascular angina, ${ }^{39}$ endothelial dysfunction, ${ }^{40-42}$ aortic stiffness, ${ }^{43}$ and vascular and metabolic abnormalities. ${ }^{44}$ Perhaps, the best study of endothelial function in NCCP was a longitudinal study by Bugiardini et al. ${ }^{40}$ Since anxiety and depression are highly comorbid with NCCP and since studies support the presence of depression and anxiety as risk factors for CAD, it is very important to know the long-term prognosis of NCCP, which at this point remains unclear. It is important to understand the long-term prognosis of NCCP so that these patients can be better treated to decrease suffering and cost. In this article, we review the literature focusing on studies that address the prognosis of NCCP patients.

\section{Objective}

To identify studies in relation to the long-term prognosis of NCCP patients including cardiovascular health risk and psychological well-being.

\section{Methods}

\section{Search strategy}

Two sources of material for inclusion in the review were identified - electronic database and reference lists from the papers reviewed. We used a multistep search process to identify published research reports related to NCCP. We initially searched the PubMed (National Library of Medicine) computer database for relevant studies. This database contains MEDLINE citations along with selected other citations. Inclusion criteria were systematic reviews, prospective studies, and retrospective surveys. We conducted a search of the PubMed database from 1970 to 2011 using the following search terms: chest pain, noncardiac chest pain, nonspecific chest pain, unexplained chest pain, prognosis of noncardiac chest pain, prognosis of angina with normal angiography, angina with normal coronary arteries, cardiac syndrome $\mathrm{X}$, non-obstructive coronary disease and variant angina, and chest pain of noncardiac origin. Reference lists of published articles were also included.

\section{Data extraction and synthesis}

A data collection sheet was designed for the review. The following data were collected: publication details, participation and setting, patient population, study design, NCCP definition, outcome measures, results, and discussion. We then manually reviewed articles obtained through the PubMed search to identify additional articles pertinent to the topic of this review. The title and abstract of each article were read, and from that relevant studies that investigated NCCP were selected. All identified studies were imported and combined into one database.

\section{Results}

Relevant studies that investigated NCCP were selected. Studies supporting worse outcome (cardiac morbidity and mortality; Table 2; $n=16$ ) comprised 173,875 total patients followed up, with mean age 57 and mean length of followup 7.5 years. Studies supporting good outcome (Table 3; $\mathrm{n}=25$ ) comprised 2,44,998 patients with age 50 and length of follow-up 5 years. Articles indicating a poor psychological outcome (psychiatric morbidity, worse quality of life) for NCCP patients (Table 4; $n=9$ ) comprised 3,987 patients and length of follow-up 2 years.

\section{Discussion}

In follow-up studies indicating worse outcome, patients were followed an average of 7.5 years compared with 5 years in studies indicating good prognosis. Also, the mean age is 57 years in the worse outcome group compared to 50 years in the good outcome group. There is some controversy about the long-term morbidity and mortality outcomes of NCCP patients. Many studies have found no significant differences in death rates in chest pain patients without CAD compared to those in the general population. ${ }^{6}$ In one such study, the 7 -year mortality rate was $4 \%$ for patients with a normal arteriogram and $8 \%$ for those whose workup had revealed mild disease. ${ }^{75}$ Another study ${ }^{53}$ following 173 patients for 12 years reported that patients being discharged from the ED with NCCP had as good a prognosis for cardiovascular outcomes as the general population of the same age - but the frequency and intensity of chest pains remained unchanged in a third of the patients over this lengthy time period. Dumville et $\mathrm{al}^{78}$ retrospectively studied 456 consecutive patients presenting with chest pain to a Rapid-Access Chest Pain Clinic in England. Of these, 235 were discharged with a diagnosis of NCCP within 14 days of their symptoms being reported. Upon follow-up (median of 5.4 months later), nearly half of the patients still had chest pain, and amongst these, more than half remained unconvinced by their negative cardiac diagnosis. ${ }^{78}$

However, these results contrast with the number of studies, ${ }^{9-13}$ which indicate that NCCP patients are at higher risk to experience adverse cardiovascular outcomes than 
Table 2 Articles supporting worse cardiovascular outcome for NCCP patients

\begin{tabular}{|c|c|c|c|c|}
\hline Investigators & Participants & Months & Outcome measures & Results \\
\hline Bodegard et al $(2004)^{45}$ & 2,014 & 312 & CABG and MI morbidity data & $\begin{array}{l}\text { Had a higher incidence of CABG }(P<0.0004) \text { and } \\
\text { acute } \mathrm{MI}(P<0.026)\end{array}$ \\
\hline Bugiardini et al (2009) ${ }^{9}$ & 7,656 & 12 & $\begin{array}{l}\text { Rates of mortality and cardiovascular } \\
\text { morbidity }\end{array}$ & $2 \%$ death rate at I-year follow-up \\
\hline $\begin{array}{l}\text { Eslick and Talley } \\
(2008)^{10}\end{array}$ & 197 & 48 & $\begin{array}{l}\text { Continued chest pain, quality of life, and } \\
\text { mortality }\end{array}$ & $\begin{array}{l}\text { The cardiac mortality rate for patients with } \\
\text { NCCP was } 5.5 \%(P=0.16)\end{array}$ \\
\hline Johnson et al $(2006)^{12}$ & 673 & 62.4 & $\begin{array}{l}\text { Cardiovascular mortality, MI, CHF, and } \\
\text { stroke }\end{array}$ & $\begin{array}{l}\text { More than twice the rate of composite } C V \\
\text { events }(P=0.03) \text {. }\end{array}$ \\
\hline Robinson et al $(2006)^{35}$ & 83,622 & 96 & CHD events in women with NCCP & $\begin{array}{l}\text { Twofold higher risk of subsequent hospitalization } \\
\text { for angina }\end{array}$ \\
\hline Rutledge et al $(2006)^{36}$ & 505 & 58.8 & Cardiovascular mortality and morbidity & Increased incidence of death and cardiac events \\
\hline $\begin{array}{l}\text { Wilhelmsen et al } \\
(1998)^{13}\end{array}$ & 6,488 & 192 & Mortality and morbidity & $\begin{array}{l}\text { The relative risk of CHD mortality among men } \\
\text { with "nonspecific chest pain" was } 2.77\end{array}$ \\
\hline $\begin{array}{l}\text { McMahon et al } \\
(2008)^{\prime \prime}\end{array}$ & 786 & 60 & Mortality & $\begin{array}{l}\text { 5-year mortality rate more than double the } \\
\text { general population }\end{array}$ \\
\hline Sekhri et al $(2007)^{46}$ & $\begin{array}{l}8,762 \\
\text { NCCP: } 6,396\end{array}$ & & Death due to CAD or ACS & 599,194 (32.4\%) with NCCP \\
\hline Bugiardini et al $(2004)^{40}$ & 42 & 120 & Endothelial function & $\begin{array}{l}\text { Twenty-two patients with vasoconstriction, } \\
\text { I3 patients with CAD }\end{array}$ \\
\hline Herlitz et al $(1998)^{47}$ & & 60 & Mortality rate & NCCP $32 \%$ \\
\hline Launbjerg et al $(1993)^{48}$ & 595 & 84 & Cardiac death & High cardiac mortality \\
\hline Ruigomez et al $(2009)^{49}$ & 3,028 & 12 & Morbidity and mortality & More likely to have IHD \\
\hline Robinson et al $(2008)^{50}$ & 571 & 85.2 & Nonfatal MI & Twofold CAD \\
\hline Munk et al $(2008)^{51}$ & 386 & 120 & IHD and mortality & Threefold high \\
\hline Gilles et al $(2006)^{52}$ & $\begin{array}{l}\text { Retrospective } \\
3,5 \text { I } 4 \text { men, } \\
3,136 \text { women }\end{array}$ & & All-cause and CVD-specific death & $\begin{array}{l}\text { Higher incidence of all-cause and CVD-specific } \\
\text { death }\end{array}$ \\
\hline
\end{tabular}

Abbreviations: ACS, acute coronary syndrome; CABG, coronary artery bypass graft; CAD, coronary artery disease; $C H D$, coronary heart disease; $C H F$, congestive heart failure; CV, cardiovascular; CVD, cardiovascular disease; IHD, ischemic heart disease; MI, myocardial infarction; NCCP, noncardiac chest pain.

the general population. Geraldine et al concluded from 786 patients discharged from an ED in the UK, following an episode of acute chest pain, that they had significantly reduced 5 -year survivals. ${ }^{11}$ Results from a primary prevention study in Göteborg, Sweden, also indicated high cardiovascular (20\%) and non-cardiovascular (18\%) mortality rates amongst patients with "chest pain who had not been considered to have angina pectoris". ${ }^{13}$ Bugiardini et $\mathrm{al}^{9}$ pooled data from three Thrombolysis in Myocardial Infarction (TIMI) trials and found a high (12.1\%) incidence of adverse (cardiac-related) events at 1 year of follow-up in those NCCP patients. That study followed 710 well-characterized NCCP patients presenting with acute chest pain but lacking obstructive CAD on angiograms and without ST segment elevations during stress tests. Likewise, a study by Johnson et al ${ }^{12}$ followed 303 NCCP patients in the Women's Ischemia Syndrome Evaluation (WISE) study and reported $20 \%$ incidence of cardiovascular events (twice the incidence in women with normal angiograms and no persistent chest pain) at a median of 5.2 years of follow-up. This risk of cardiovascular events was not as high as in patients with chest pain plus obstructive CAD ( $n=263)$, which was $40 \%$, but the risk was still twice as high as in healthy controls. ${ }^{12}$ Verification of the findings of Johnson et al has been reported by Eslick et a $1^{10}$ for NCCP patients under 65 years of age in Australia: higher rates of cardiac mortality over 4 years for NCCP patients $(6 \%$ cardiac mortality) and also for CAD chest pain patients $(11 \%) .{ }^{10}$ The longest study was a 26-year follow-up of men with "possible angina" based on chest pain reported in a questionnaire but no abnormal stress test compared to men with negative responses on the chest pain questionnaire and a normal stress test. ${ }^{45} \mathrm{At}$ 26 years, men with this kind of NCCP had a CHD mortality of $25 \%$ compared to $14 \%$ among men with no symptoms of angina. The NCCP patients also had a higher incidence of coronary artery bypass grafting and acute myocardial infarctions (MIs).

In summary, there are studies indicating that NCCP patients are not at higher risk of cardiac events, and there are studies indicating that NCCP patients are at higher risk of cardiac events. All studies agree that the chest pain 
Table 3 Articles supporting NCCP as a benign problem or with good cardiovascular outcome

\begin{tabular}{|c|c|c|c|c|}
\hline Investigators & Participants & Months & Outcome measures & Results \\
\hline Scholtz et $\mathrm{al}^{53}$ & 185 & 144 & Fatal or nonfatal myocardial infarction & Good long-term prognosis \\
\hline Karlson et $\mathrm{a}^{54}$ & 2,102 & 12 & Mortality & Mortality $3 \%$ \\
\hline Walker et $\mathrm{al}^{55}$ & 487 & 1 & Acute myocardial infarction, death, $\mathrm{PCl}$ & $2.1 \%$ adverse cardiac events \\
\hline Bargheer et al ${ }^{56}$ & 178 & 177.6 & Mortality, MI & Excellent long-term prognosis \\
\hline Voelker et $\mathrm{al}^{57}$ & 88 & 110.4 & Death, Ml & Three deaths, one MI \\
\hline Foussas et $\mathrm{al}^{58}$ & 160 & 30 & Death, MI & Excellent prognosis \\
\hline Lamendola et $\mathrm{a}^{59}$ & 155 & 137 & Cardiac death, AMI & Excellent long-term prognosis \\
\hline Lichtlen et al ${ }^{60}$ & 176 & 148.8 & Coronary event & Good long-term prognosis \\
\hline Isner et $a^{|6|}$ & 121 & 51.6 & Morbidity, cardiac events & High favorable prognosis \\
\hline Pasternak et al ${ }^{62}$ & 175 & 42.7 & Chest pain & Low mortality and morbidity \\
\hline Dart et $\mathrm{al}^{63}$ & 98 & $\begin{array}{l}\text { Retrospective } \\
\text { review }\end{array}$ & Life expectancy & Excellent prognosis \\
\hline Van Dorpe et $a^{164}$ & 142 & 49.3 & Cardiac death & No cardiac death, one MI \\
\hline Panju el $a^{65}$ & 158 & 36 & Mortality & Low mortality rate \\
\hline Williams et $\mathrm{al}^{66}$ & 161 & 117.6 & Survival & No significant difference \\
\hline \multirow[t]{2}{*}{ Spalding et $\mathrm{a}^{67}$} & 250 & 12 & Mortality rate & $2.9 \%$ in NCCP \\
\hline & NCCP 108 & & & \\
\hline Rey et $\mathrm{a}^{68}$ & 104 & 44.4 & Pain & Favorable life prognosis \\
\hline Roll et $\mathrm{a}^{69}$ & 64 & 60 & Pain & Excellent prognosis \\
\hline \multirow[t]{2}{*}{ Launbjerg et al ${ }^{70}$} & 204 & 33 & Cardiac death, nonfatal AMI & Three events among I 40 patients \\
\hline & NCCP I40 & & & \\
\hline \multirow[t]{2}{*}{ Fagring et $\mathrm{al}^{71}$} & 235,855 & 12 & I-year mortality & Similar to general population \\
\hline & Registry study & & & \\
\hline Zarauza et $\mathrm{al}^{72}$ & 93 & 12 & Coronary events & Good I-year outcome \\
\hline Colon et $\mathrm{a}^{73}$ & 105 & 33.6 & Ml, cardiac death & Excellent 3-year prognosis \\
\hline Bringager et $\mathrm{a}^{74}$ & 199 patients & & Long-term outcome, death rate & Low death rate \\
\hline \multirow[t]{2}{*}{ Kemp et $\mathrm{al}^{75}$} & 21,487 consecutive & 84 & The effect on 7-year survival & The 7 -year survival rate was $96 \%$ \\
\hline & coronary arteriograms & & & \\
\hline Hirota et $\mathrm{al}^{76}$ & 274 & 72 & Fatal or nonfatal MI & None \\
\hline Prina et $\mathrm{a}^{77}$ & I,973 (NCCP: 230) & & Adverse cardiac event, mortality & $\begin{array}{l}\text { Without risk factors, cardiac } \\
\text { outcome is excellent }\end{array}$ \\
\hline
\end{tabular}

Abbreviations: AMI, acute myocardial infarction; Ml, myocardial infarction; NCCP, noncardiac chest pain; PCl, percutaneous coronary intervention.

Table 4 Articles supporting poor psychological outcome for NCCP patients

\begin{tabular}{|c|c|c|c|c|}
\hline Investigators & Participants & Months & Outcome & Results \\
\hline Bringager et $\mathrm{al}^{74}$ & 199 & 108 & $\begin{array}{l}\text { Mortality, health-related } \\
\text { quality of life }\end{array}$ & Panic disorder has a negative long-term effect \\
\hline Dumville et $\mathrm{al}^{78}$ & $\begin{array}{l}235 \\
\text { (retrospective data) }\end{array}$ & & Chest pain & Half of NCCP patients reported ongoing chest pain \\
\hline Karlson et $\mathrm{al}^{54}$ & 2,102 & 12 & Mortality, AMI, & More emotional and psychosomatic symptoms \\
\hline Karlson et $\mathrm{al}^{79}$ & & 12 & Chest pain, well-being & More chest pain, worse quality of life \\
\hline Ockene et $\mathrm{a}^{80}$ & 57 & 15 & Functional status & $\begin{array}{l}\text { Many patients remained } \\
\text { limited in activity }\end{array}$ \\
\hline Bass and Jackson ${ }^{81}$ & 30 & 12 & Psychosocial status & Psychiatric morbidity, chronic course \\
\hline Roll et $\mathrm{a}^{69}$ & 64 & 60 & Chest pain, depression & High psychological symptoms \\
\hline Fagring et $\mathrm{a}^{82}$ & 1,069 & & Quality of life & Poor \\
\hline Jerlock et $\mathrm{al}^{83}$ & 231 & & Quality of life & Poor \\
\hline
\end{tabular}

Abbreviations: AMI, acute myocardial infarction; NCCP, noncardiac chest pain.

commonly persists in NCCP patients for many years. At least $50 \%$ of the NCCP patients have an Axis I psychiatric diagnosis. Depression is an established risk factor for CVD. By last count, 12 long-term prospective studies have clearly established that there is about a 2.0 relative risk of adverse cardiovascular events associated with depression. ${ }^{29,30}$ It is possible that NCCP patients in the long run may have poor cardiovascular outcome, and studies are needed to determine if depression and anxiety play a role. Is there an association between anxiety, depression, and CVD that could explain 
the possible association of NCCP and long-term morbidity and mortality? Another important aspect is the heterogeneity of NCCP. The NCCP group includes many patients with a history of established CAD and NCCP.

\section{Conclusion}

The literature we have searched contains mixed findings in relation to long-term medical and psychological prognosis in patients with NCCP. The findings from this review show that there are mixed data on long-term morbidity, cardiovascular adverse events, and mortality of NCCP, some supporting evidence for poor outcome and others supporting evidence for positive outcome. Articles supporting poor outcome had longer follow-ups and included patients of higher age. Bodegard et $\mathrm{al}^{45}$ followed their subjects for 26 years. Articles supporting poor long-term outcome tend to include NCCP patients with high preexisting cardiac risk factors, namely, endothelial dysfunction (Bugiardini et $\mathrm{al}^{40}$ ), higher TIMI score family history, hypertension, hypercholesterolemia, diabetes mellitus (Bugiardini et $\mathrm{al}^{9}$ ), and increased cardiovascular risk factors (Wilhelmsen et $\mathrm{al}^{13}$. Studies supporting good cardiovascular outcome included young adults who had less cardiac risk factors. ${ }^{56}$ Lichtlen et $\mathrm{al}^{60}$ reported that NCCP patients experiencing a coronary event had significantly more risk factors like hypercholesterolemia, hypertension, smoking, and diabetes mellitus than those without a coronary event. One possible conclusion could be that age $\geq 55$ years with increased cardiac risk factors could confer a long-term cardiovascular risk compared with NCCP patients between 45 and 50 years of age with less risk factors. More studies are needed to determine if this risk is higher than in the general population aged $\geq 55$ years without NCCP.

It is possible that NCCP patients in the long run may have poor cardiovascular outcome, and studies are needed to determine if depression and anxiety play a role. ${ }^{84}$ The heterogeneity of NCCP and the study populations included in the literature limit definitive conclusions. A number of studies have addressed cardiovascular changes in these patients. However, many patients with NCCP have prolonged psychiatric morbidity and poor quality of life. Several questions remain about NCPP with respect to the psychopathology and pathophysiology of this condition, and these patients are poorly understood leading to challenges in their care. Often labeled as "psychogenic", these patients are dismissed without proper reassurance, education about their complaint, and specific preventive measures they should take. This leads to further frustration, patient suffering, and cost.

Whether NCCP patients have good or bad outcome, these patients need careful risk stratification. ${ }^{84}$ The following should be regularly emphasized: weight reduction, smoking cessation, diet monitoring, lipid control, and treating anxiety and depression. There is evidence supporting an association between low heart rate variability (HRV) and depression ${ }^{85}$; therefore, measuring HRV could be helpful in NCCP patients. As endothelial function, arterial compliance, and pulse wave reflections serve as independent, prognostic markers of cardiovascular morbidity and mortality, ${ }^{86}$ any subclinical CVD (endothelial dysfunction) could be identified by pulse-wave analysis and velocity, a noninvasive, FDA-approved technique. ${ }^{87}$ Pulse-wave velocity and HRV could be measured in conjunction with a 3-lead ECG. Personality inventories focusing on anger and anxiety such as the Spielberger StateTrait Anxiety Inventory ${ }^{88}$ and Spielberger Anger Expression Inventory ${ }^{89}$ would be very useful rating instruments that could provide valuable insight into the personality structure and emotional status of the patient.

\section{Disclosure}

The authors report no conflicts of interest in this work.

\section{References}

1. McCaig LF, Nawar EW, National Hospital Ambulatory Medical Care Survey: 2004 Emergency Department Summary, Advance Data, From Vital and Health Statistics, Division of Health Care Statistics, Center for Disease Control; 372, June 23; 2006. Available from: https://www. cdc.gov/nchs/data/ad/ad372.pdf

2. Reis SE, Holubkov R, Conrad Smith AJ, et al. Coronary microvascular dysfunction is highly prevalent in women with chest pain in the absence of coronary artery disease: results from the NHLBI WISE study. Am Heart J. 2001;141(5):735-741.

3. Husser D, Bollmann A, Kuhne C, Molling J, Klein HU. Evaluation of noncardiac chest pain: diagnostic approach, coping strategies and quality of life. Eur J Pain. 2006;10(1):51-55.

4. McCullough PA, Ayad O, O'Neil WW, Goldstein JA. Costs and outcomes of patients admitted with chest pain and essentially normal electrocardiograms. Clin Cardiol. 1998;21(1):22-26.

5. Eslick GD, Coulshed DS, Talley NJ. Review article: the burden of illness of non-cardiac chest pain. Aliment Pharmacol Ther. 2002;16:1217-1223.

6. Gorenberg M, Marmor A, Rotstein H. Detection of chest pain of noncardiac origin at the emergency room by a new non-invasive device avoiding unnecessary admission to hospital. Emerg Med J. 2005;22: 486-489.

7. Sanders D, Bass C, Mayou RA, Goodwin S, Bryant BM, Tyndel S. Noncardiac chest pain: why was a brief intervention apparently ineffective? Psychol Med. 1997;27(5):1033-1040.

8. Jerlock M, Gaston-Johansson F, Danielson E. Living with unexplained chest pain. J Clin Nurs. 2005;14(8):956-964.

9. Bugiardini R, Manfrini O, De Ferrari GM. Unanswered questions for management of acute coronary syndrome: risk stratification of patients with minimal disease or normal findings on coronary angiography. Arch Intern Med. 2006;166(13):1391-1395. 
10. Eslick GD, Talley NJ. Natural history and predictors of outcome for non-cardiac chest pain: a prospective 4-year cohort study. Neurogastroenterol Motil. 2008;20(9):989-997.

11. McMahon CG, Yates DW, Hollis S. Unexpected mortality in patients discharged from the emergency department following an episode of nontraumatic chest pain. Eur J Emerg Med. 2008;15(1):3-8.

12. Johnson BD, Shaw LJ, Pepine CJ, et al. Persistent chest pain predicts cardiovascular events in women without obstructive coronary artery disease. Results from the NIH-NHLBI-sponsored Women's Ischaemia Syndrome Evaluation (WISE) study. Eur Heart J. 2006;27(12):1408-1415.

13. Wilhelmsen L, Rosengren A, HagmanM, Lappas G. "Nonspecific" chest pain associated with high long-term mortality: results from the primary prevention study in Goteborg, Sweden. Clin Cardiol. 1998;21(7):477-482.

14. Alexander PJ, Prabhu SG, Krishnamoorthy ES, Halkatti PC. Mental disorders in patients with noncardiac chest pain. Acta Psychiatr Scand. 1994;89(5):291-293.

15. Hocaoglu C, Gulec MY, Durmus I. Psychiatric comorbidity in patients with chest pain without a cardiac etiology. Isr J Psychiatry Relat Sci. 2008;45:49-54.

16. Ayuso Mateos JL, Bayon Perez C, Santo-Domingo Carrasco J, Olivares D. Atypical chest pain and panic disorder. Psychother Psychosom. 1989;52(1-3):92-95.

17. Basha I, Mukerji V, Langevin P, Kushner M, Alpert M, Beitman BD. Atypical angina in patients with coronary artery disease suggests panic disorder. Int J Psychiatry Med. 1989;19(4):341-346.

18. Beitman BD. Panic disorder in patients with angiographically normal coronary arteries. Am J Med. 1992;92(5A):33S-40S.

19. Fleet RP, Dupuis G, Marchand A, et al. Detecting panic disorder in emergency department chest pain patients: a validated model to improve recognition. Ann Behav Med. 1997;19(2):124-131.

20. Kushner MG, Beitman BD, Beck NC. Factors predictive of panic disorder in cardiology patients with chest pain and no evidence of coronary artery disease: a cross-validation. J Psychosom Res. 1989;33(2) 207-215.

21. Ho KY, Kang JY, Yeo B, Ng W1. Non-cardiac, non-oesophageal chest pain: the relevance of psychological factors. Gut. 1998;43(1):105-110.

22. White KS, Raffa SD, Jakle KR, et al. Morbidity of DSM-IV Axis disorders in patients with noncardiac chest pain: psychiatric morbidity linked with increased pain and health care utilization. J Consult Clin Psychol. 2008;76(3):422-430.

23. Van Handel D, Fass R. The pathophysiology of non-cardiac chest pain. J Gastroenterol Hepatol. 2005;20(Suppl):S6-13.

24. Fang J, Bjorkman D. A critical approach to noncardiac chest pain: pathophysiology, diagnosis, and treatment. Am J Gastroenterol. 2001;96(4):958-968.

25. Lembo AJ. Visceral hypersensitivity in noncardiac chest pain. Gastroenterol Clin North Am. 2004;33(1):55-60.

26. Nguyen TM, Eslick GD. Systematic review: the treatment of noncardiac chest pain with antidepressants. Aliment Pharmacol Ther. 2012;35(5):493-500.

27. Kawachi I, Colditz GA, Ascherio A, et al. Prospective study of phobic anxiety and risk of coronary heart disease in men. Circulation. 1994;89(5):1992-1997.

28. Kawachi I, Sparrow D, Vokonas PS, Weiss ST. Symptoms of anxiety and risk of coronary heart disease. Circulation. 1994;90(5): 2225-2229.

29. Ariyo AA, Haan M, Tangen CM, et al. Depressive symptoms and risks of coronary heart disease and mortality in elderly Americans. Circulation. 2000;102:1773-1779.

30. Wassertheil-Smoller S, Shumaker S, Ockene J, et al. Depression and cardiovascular sequelae in postmenopausal women. The Women's Health Initiative (WHI). Arch Intern Med. 2004;164(3):289-298.

31. Bajwa WK, Asnis GM, Sanderson WC, et al. High cholesterol levels in patients with panic disorder. Am J Psychiatry. 1992;149(3):376-378.
32. Hayward C, Taylor CB, Roth WT, King R, Agras WS. Plasma lipid levels in patients with panic disorder or agoraphobia. Am J Psychiatry. 1989;146(7):917-919.

33. Bugiardini R, Bairey Merz CN. Angina with "normal" coronary arteries: a changing philosophy. JAMA. 2005;293(4):477-484.

34. Cannon RO, Balaban RS. Chest pain in women with normal coronary angiograms. N Eng J Med. 2000;342(12):885-887.

35. Robinson JG, Wallace R, Limacher M, et al. Elderly women diagnosed with nonspecific chest pain may be at increased cardiovascular risk. J Womens Health (Larchmt). 2006;15(10):1151-1160.

36. Rutledge T, Reis SE, Olson MB, et al. Depression symptom severity and reported treatment history in the prediction of cardiac risk in women with suspected myocardial ischemia. The NHLBI-sponsored WISE study. Arch Gen Psychiatry. 2006;63(8):874-880.

37. Chambers J, Bass C. Chest pain with normal coronary anatomy: a review of natural history and possible etiologic factors. Prog Cardiovasc Dis. 1990;33(3):161-184.

38. Nemes A, Forster T, Csanady M. Diminished Coronary flow velocity reserve and aortic distensibility in elderly patients with chest pain and negative coronary angiograms. Aging Clin Exp Res. 2008;20(4): 297-301.

39. Cannon RO 3rd, Epstein SE. Microvascular angina as a cause of chest pain with angiographically normal coronary arteries. Am J Cardiol. 1988;61(15):1338-1343.

40. Bugiardini R, Manfrini O, Pizzi C, Fontana F, Morgagni G. Endothelial function predicts future development of coronary artery disease: a study of women with chest pain and normal coronary angiograms. Circulation. 2004;109(21):2518-2523.

41. Kidawa M, Krzeminska-Pakula M, Peruga JZ, Kasprzak JD. Arterial dysfunction in syndrome $\mathrm{X}$ : results of arterial reactivity and pulse wave propagation tests. Heart. 2003;89(4):422-426.

42. Quyyumi AA, Cannon RO, Panza JA, et al. Endothelial dysfunction in patients with chest pain and normal coronary arteries. Circulation. 1992;86(6):1864-1871.

43. Choi CU, Park EB, Suh SY, et al. Impact of aortic stiffness on cardiovascular disease in patients with chest pain: assessment with direct intra-arterial measurement. Am J Hypertens. 2007:20(11): 1163-1169.

44. Botker HE. Vascular and metabolic abnormalities in patients with angina pectoris and normal coronary angiograms. Dan Med Bull. 2001;48(1):1-18.

45. Bodegard J, Erikssen G, Bjornholt JV, Thelle D, Erikssen J. Possible angina detected by the WHO angina questionnaire in apparently healthy men with a normal exercise ECG: coronary heart disease or not? A 26 year follow up study. Heart. 2004;90(6):627-632.

46. Sekhri N, Feder GS, Junghans C, Hemingway H, Timmis AD. How effective are rapid access chest pain clinics? Prognosis of incident angina and non-cardiac chest pain in 8762 consecutive patients. Heart. 2007;93(4):458-463.

47. Herlitz J, Hjalmarson A, Karlson BW, Nyberg G. Long-term morbidity in patients where the initial suspicion of myocardial infarction was not confirmed. Clin Cardiol. 1988;11(4):209-214.

48. Launbjerg J, Fruergaard P, Jacobsen HL, Madsen JK. Long-term cardiac mortality in patients admitted with noncoronary chest pain under suspicion of acute myocardial infarction. Cardiology. 1993;82(1):36-41.

49. Ruigómez A, Massó-González EL, Johansson S, Wallander MA, GarcíaRodríguez LA. Chest pain without established ischemic heart disease in primary care patients: associated comorbidities and mortality. $\mathrm{Br} J$ Gen Pract. 2009;59(560):e78-e86.

50. Robinson JG, Wallace R, Limacher M, et al. Cardiovascular risk in women with non-specific chest pain (from the Women's Health Initiative Hormone Trials). Am J Cardiol. 2008;102(6):693-699.

51. Munk EM, Nørgård B, Dethlefsen C, et al. Unexplained chest/epigastric pain in patients with normal endoscopy as a predictor for ischemic heart disease and mortality: a Danish 10-year cohort study. BMC Gastroenterol. 2008;8:28. 
52. Gillies M, Jhund PS, MacTeague K, et al. Prior psychiatric hospitalization is associated with excess mortality in patients hospitalized with non-cardiac chest pain: a data linkage study based on the full Scottish population 1991-2006. Eur Heart J. 2012;33(6):760-767.

53. Scholz M, Wegener K, Unverdorben M, Klepzig H. [Long-term outcome in patients with angina-like chest pain and normal coronary angiograms]. Herz. 2003;28(5):413-420. German.

54. Karlson BW, Wiklund I, Bengston A, Herlitz J. Prognosis and symptoms one year after discharge from the emergency department in patients with acute chest pain. Chest. 1994;105(5):1442-1447.

55. Walker NJ, Sites FD, Shofer FS, Hollander JE. Characteristics and outcomes of young adults who present to the emergency department with chest pain. Acad Emerg Med. 2001;8(7):703-708.

56. Bargheer K, Trappe HJ, Wenzlaff P, Lichtlen PR. [Long-term follow-up of patients with angina pectoris-like chest pain and normal coronary angiogram]. Z Kardiol. 1993;82(1):8-16. German.

57. Voelker W, Euchner U, Dittmann H, Karsch KR. Long-term clinical course of patients with angina and angiographically normal coronary arteries. Clin Cardiol. 1991;14(4):307-311.

58. Foussas SG, Adamopoulou EN, Kafaltis NA, et al. Clinical characteristics and follow-up of patients with chest pain and normal coronary arteries. Angiology. 1998;49(5):349-354.

59. Lamendola P, Lanza GA, Spinelli A, et al. Long-term prognosis of patients with cardiac syndrome X. Int J Cardiol. 2010;140(2): 197-199.

60. Lichtlen PR, Bargheer K, Wenzlaff P. Long-term prognosis of patients with angina-like chest pain and normal coronary angiographic findings. J Am Coll Cardiol. 1995;25(5):1013-1018.

61. Isner JM, Salem DN, Banas JS Jr, Levine HJ. Long-term clinical course of patients with normal coronary arteriography: follow-up study of 121 patients with normal or nearly normal coronary arteriograms. Am HeartJ. 1981;102(4):645-653.

62. Pasternak RC, Thibault GE, Savoia M, DeSanctis RW, Hutter AM Jr. Chest pain with angiographically insignificant coronary arterial obstruction. Clinical presentation and long-term follow-up. Am J Med. 1980;68(6):813-817.

63. Dart AM, Davies HA, Dalal J, Ruttley M, Henderson AH. Diagnosis and prognosis of chest pain with normal coronary arteriograms. Acta Med Scand Suppl. 1981;644:74-76.

64. Van Dorpe A, Piessens J, Willems JL, De Geest H. Unexplained chest pain with normal coronary arteriograms. A follow-up study. Cardiology. 1987;74(6):436-443.

65. Panju A, Farkouh ME, Sackett DL, et al. Outcome of patients discharged from a coronary care unit with a diagnosis of "chest pain not yet diagnosed". CMAJ. 1996;155(5):541-546.

66. Williams JF, Sontag SJ, Schnell T, Leya J. Non-cardiac chest pain: the long-term natural history and comparison with gastroesophageal reflux disease. Am J Gastroenterol. 2009;104(9):2145-2152.

67. Spalding L, Reay E, Kelly C. Cause and outcome of atypical chest pain in patients admitted to hospital. J R Soc Med. 2003;96(3):122-125.

68. Rey E, Roncero García-Escribano O, Alvarez Sánchez A, Díaz-Rubio M. Long-term outcome of patients with non-cardiac chest pain. Rev Esp Enferm Dig. 2002;94(1):25-33. English, Spanish.

69. Roll M, Kollind M, Theorell T. Five-year follow-up of young adults visiting an emergency unit because of atypical chest pain. $J$ Intern Med. 1992;231(1):59-65.

70. Launbjerg J, Fruergaard P, Hesse B, Jørgensen F, Elsborg L, Petri A. Long-term risk of death, cardiac events and recurrent chest pain in patients with acute chest pain of different origin. Cardiology. 1996;87(1): 60-66.
71. Fagring AJ, Lappas G, Kjellgren KI, Welin C, Manhem K, Rosengren A. Twenty-year trends in incidence and 1-year mortality in Swedish patients hospitalised with non-AMI chest pain. Data from 1987-2006 from the Swedish hospital and death registries. Heart. 2010;96(13):1043-1049.

72. Zarauza J, Rodríguez-Lera MJ, Ceballos B, Piedra L, Dierssen T, Pérez J. [Follow-up findings one year after discharge from a chest pain unit]. Rev Esp Cardiol. 2003;56(11):1137-1140. Spanish.

73. Colon PJ 3rd, Cheirif J. Long-term value of stress echocardiography in the triage of patients with atypical chest pain presenting to the emergency department. Echocardiography. 1999;16(2):171-177.

74. Bringager CB, Friis S, Arnesen H, Dammen T. Nine-year follow-up of panic disorder in chest pain patients: clinical course and predictors of outcome. Gen Hosp Psychiatry. 2008;30(2):138-146.

75. Kemp HG, Kronmal RA, Vlietstra RE, Frye RL. Seven year survival of patients with normal or near normal coronary arteriograms: a CASS registry study. J Am Coll Cardiol. 1986;7(3):479-483.

76. Hirota Y, Ohnaka H, Tsuji R, et al. Excellent prognosis of Japanese patients with chest pain and normal or nearly normal coronary arteries 2- to 13-year follow-up of 274 patients after coronary cineangiography. Jpn Circ J. 1994;58(1):43-48.

77. Prina LD, Decker WW, Weaver AL, et al. Outcome of patients with a final diagnosis of chest pain of undetermined origin admitted under the suspicion of acute coronary syndrome: a report from the Rochester Epidemiology Project. Ann Emerg Med. 2004;43(1):59-67.

78. Dumville JC, MacPherson H, Griffith K, Miles JN, Lewin RJ. Noncardiac chest pain: a retrospective cohort study of patients who attended a Rapid Access Chest Pain Clinic. Fam Pract. 2007;24(2):152-157.

79. Karlson BW, Wiklund I, Bengtson A, Herlitz J. Prognosis, severity of symptoms, and aspects of well-being among patients in whom myocardial infarction was ruled out. Clin Cardiol. 1994;17(8):427-431.

80. Ockene IS, Shay MJ, Alpert JS, Weiner BH, Dalen JE. Unexplained chest pain in patients with normal coronary arteriograms: a follow-up study of functional status. $N$ Engl J Med. 1980;303(22):1249-1252.

81. Bass C, Jackson G. Angina with normal coronary arteriograms. Clinical status at one year. Arch Mal Coeur Vaiss. 1983;76:237-245.

82. Fagring AJ, Kjellgren KI, Rosengren A, Lissner L, Manhem K, Welin C. Depression, anxiety, stress, social interaction and health-related quality of life in men and women with unexplained chest pain. $B M C$ Public Health. 2008;8:165.

83. Jerlock M, Kjellgren KI, Gaston-Johansson F, et al. Psychosocial profile in men and women with unexplained chest pain. J Intern Med. 2008;264(3):265-274.

84. Pitt B. Increased cardiovascular risk associated with non-cardiac chest pain in patients with a prior psychiatric hospitalization: an opportunity and challenge for both the psychiatrist and the cardiologist. Eur Heart J. 2012;33(6):692-694.

85. Pizzi C, Manzoli L, Mancini S, Costa GM. Analysis of potential predictors of depression among coronary heart disease risk factors including heart rate variability, markers of inflammation, and endothelial function. Eur Heart J. 2008;29(9):1110-1117.

86. Weber T, Auer J, O'Rourke MF, et al. Arterial stiffness, wave reflections, and the risk of coronary artery disease. Circulation. 2004;109(2):184-189.

87. Hayward CS, Avolio AP, O'Rourke MF. Arterial pulse wave velocity and heart rate. Hypertension. 2002;40(6):e8-e9.

88. Marteau TM, Bekker H. The development of a six-item short-form of the state scale of the Spielberger State-Trait Anxiety Inventory (STAI). Br J Clin Psychol. 1992;31(Pt 3):301-306.

89. Spielberger CD. State-Trait Anger Expression Inventory. Corsini Encyclopedia of Psychology. Hoboken: John Wiley \& Sons; 2010. 
Research Reports in Clinical Cardiology

Research Reports in Clinical Cardiology is an international, peerreviewed, open access journal publishing original research, reports,

Visit http://www.dovepress.com/testimonials.php to read real quotes editorials, reviews and commentaries on all areas of cardiology in the clinic and laboratory. The manuscript management system is completely online and includes a very quick and fair peer-review system.

Submit your manuscript here: https://www.dovepress.com/research-reports-in-clinical-cardiology-journal 